\title{
Climate Change and the Geographic Distribution of Infectious Diseases
}

\author{
Joshua Rosenthal \\ Division of International Training and Research, Fogarty International Center, National Institutes of Health, Bethesda, MD
}

\begin{abstract}
Our ability to predict the effects of climate change on the spread of infectious diseases is in its infancy. Numerous, and in some cases conflicting, predictions have been developed, principally based on models of biological processes or mapping of current and historical disease statistics. Current debates on whether climate change, relative to socioeconomic determinants, will be a major influence on human disease distributions are useful to help identify research needs but are probably artificially polarized. We have at least identified many of the critical geophysical constraints, transport opportunities, biotic requirements for some disease systems, and some of the socioeconomic factors that govern the process of migration and establishment of parasites and pathogens. Furthermore, we are beginning to develop a mechanistic understanding of many of these variables at specific sites. Better predictive understanding will emerge in the coming years from analyses regarding how these variables interact with each other.
\end{abstract}

Keywords: Climate models disease spread, biological models, mapping disease, socioeconomic conditions, prediction

\section{INTRODUCTION}

Scientists and public health officials have observed and mapped the geographical incidence of infectious diseases in relation to weather and climate for hundreds of years, and formally for at least a half century (Reisen, 2010). In recent years, this work has accelerated significantly in the context of predictions for global climate change (IPCC, 2007b). The development of and response to the IPCC 4 predictions of probable increases of vector-borne and diarrheal diseases during coming decades (IPCC, 2007a) has catalyzed a great deal of research, analysis, and speculation regarding the nature, magnitude, and extent of possible changes.

Published online: May 25, 2010

Correspondence to: Joshua Rosenthal, e-mail: joshua_rosenthal@nih.gov
Numerous, and in some cases conflicting, predictions have been developed regarding the frequency, severity, and duration of epidemics that may emerge. With respect to the biogeographical focus of this issue, the central question is whether pathogens and parasites that are currently restricted to tropics and lower latitudes where the world's greatest biodiversity lies move toward poles (mostly north) and upward in altitude. Perhaps the more controversial topic today is the corollary to this question-how much will future ranges of diseases that that do move be constrained by socioeconomic conditions, including our capacity to control them (Hay et al., 2002; Patz et al., 2005; Lafferty, 2009)?

Until very recently, climate projections for the coming decades have been limited to very coarse scale projections using Global Circulation Models (GCMs) at the level of continents and gross latitudinal and altitudinal changes 
(Fowler et al., 2007). Downscaling such climate models is still in its infancy and only beginning to be useful for ecological and public health research at the regional, national, and sub-national scale for which most species distribution studies are conducted and validated (Beaumont et al., 2008). As such, epidemiologists, ecologists, geographers, and others are grappling with the implications of global climate projections for infectious diseases using a variety of approaches. These include biological process models, statistical geospatial analysis of current and historical prevalence and incidence, and macroeconomic demographic models, all coupled with climate analyses and projections.

Although we are still at an early stage in our ability to make predictions for these extraordinarily complex phenomena, we are beginning to see some general patterns with regard to the important geophysical factors that govern biological basis for distribution change, the role of transport of disease, vectors and hosts, the biotic assemblages that influence establishment, and the socioeconomic conditions that constrain or enhance these dynamics.

\section{Geophysical Factors: Temperature AND PReCIPITATION}

Underlying most predictions for climate change effects on parasite and pathogen distribution are the physiological factors that regulate survivorship, reproduction, and transmission, and their interaction with extrinsic environmental changes associated with climate: precipitation, humidity, air and water temperature, principally. Under moderate greenhouse gas emission scenarios, GCM models project during the next century approximately $2-4^{\circ} \mathrm{C}$ average warming and greater precipitation at higher latitudes, with decreased precipitation at lower latitudes, and increases in heavy precipitation events in many regions (IPCC, 2007b).

Biological process models are an important component of the discussion. Biological models estimate the responsiveness and thresholds of parasites, pathogens, and vectors to temperature and precipitation. These models can be used to estimate survivorship, transmissibility, and reproduction, including estimates of R0 - the basic reproductive ratio-under different climate scenarios (see Lafferty, 2009 for review). Based largely on studies of vector and/or parasite development, warming and increases in humidity are predicted to open up new zones for malaria in Africa (Epstein et al., 1998; Martens, 1999), parasitic nematodes in the Arctic (Kutz et al., 2005), West Nile Virus (Reisen et al., 2006), Lyme disease in North America (Ogden et al., 2008), and Schistosomiasis in China (Zhou et al., 2008). Historical analyses of climate patterns coupled with these biological process models provide additional explanatory power. For example, observed altitudinal increases in falciparum malaria in the East African highlands during the past 30 years have been associated with increasing temperatures and are consistent with models of anopheline mosquito vector development (Pascual et al., 2006).

Process models also suggest, as one would expect, that in some cases, the same climate trends may reduce survivorship or transmission of pathogens, parasites, and their vectors at the warmer boundaries of their current ranges (Lafferty, 2009). That is because future temperatures may exceed the biological thresholds for survival or transmission at these boundaries. More analysis of biological maxima and minima of pathogens, parasites, and their vectors, including their diurnal fluctuation thresholds, in concert with downscaled climate models or historical records will be helpful in this regard. Paaijmans et al. (2009) analyzed development time of Plasmodium falciparum parasites in relation to that of its vector under a range of diurnal temperature fluctuations. They found that at the higher mean temperatures $\left(>26^{\circ} \mathrm{C}\right)$ associated with endemic malaria transmission in Africa effects of global warming on malaria dynamics may be overestimated. However, at lower mean temperatures associated with epidemic outbreaks $\left(<20^{\circ} \mathrm{C}\right)$, such as those found in the Kenyan Highlands, real increases in $\mathrm{R}_{0}$ with a couple degrees of warming are biologically possible, and consistent with epidemiological trends during the past 20 years in that region.

Similarly, changes in seasonality, especially intensity of rainfall, has been shown to be important in several diseases (Koelle et al., 2005; Altizer et al., 2006; Pascual et al., 2008), particularly cholera dynamics. More frequent heavy rainfall events are predicted to occur in some areas, although the confidence levels and scaling of these future precipitation models may still be insufficient to support geographically specific predictions.

Whereas vector-borne diseases, and to a lesser extent diarrheal diseases, have been the principal focus of discussion, directly transmitted diseases, such as influenza and cold viruses, are likely to change as well. Recent laboratory work (Shaman and Kohn, 2009) on the persistence and 
transmission efficiency of influenza has shown the virus to be constrained markedly by absolute humidity. More recent epidemiological analysis support this finding (Shaman et al., 2010) and suggest that the marked seasonality and generally predictable geographical trajectory of seasonal influenza likely reflect, at least in part, climate variables.

Analyses of biological processes in relation to climaterelevant geophysical parameters establish the potential for climate change effects. However, they are insufficient to explain the highly complex dynamics of infectious disease transmission and establishment, including biological, climatological and socioeconomic considerations.

A frequently used alternative approach to predicting biogeographic spread is based on mapping the statistics of current and historical disease or vector prevalence or transmission coupled with climate projections, often based on GCMs (Rogers and Randolph, 2000; Mabaso et al., 2006; Ebi et al., 2007). More recent statistical mapping (also called niche modeling) approaches have been able to use downscaled climate models (de la Rocque, 2008) in their projections. Several have predicted northward shifting zones of infection with modest impacts on overall extent of distribution (Rogers and Randolph, 2000; Hay et al., 2004; Nakazawa et al., 2007). Although essential, many of these statistical mapping projects make their own set of assumptions. Particularly problematic are those that assume that today's public health and socioeconomic conditions, including surveillance and control capabilities, populations affected, and other ecological and economic conditions, will be similar to future conditions at new locations.

\section{Transport to New Climate-Friendly REGIONS}

One significant and long-presumed constraint on longrange biogeographical spread of invasive species, including pathogens, parasites, vectors, and hosts, has been the role of spatial distance on the ability to arrive at a new hospitable site (MacArthur and Wilson, 1967; Reperant, 2009). This is, of course, less of a constraint today and for the foreseeable future due to a diversity of globalized transport opportunities. Specifically, agriculture trade (Arzt et al., 2010), livestock movement (Fevre et al., 2006), wildlife trade (Karesh et al., 2005), human travel and migration (MacPherson et al., 2009), ship ballast water (Aguirre-Macedo et al., 2008), auto tire trade (Hawley et al., 1987), and the global transport of desert dust containing microbiota regularly move pathogens, vectors, and infected hosts all around the Earth.

At small and intermediate scales, distance is still a very important determinant of disease movement. For example, Triatomine vector dispersal of Chagas disease in Argentina at a scale of meters to a few kilometers ( $\mathrm{Zu}$ Dohna et al., 2009) or movement of African trypanosomiasis at a scale of tens to hundreds of kilometers via animal migrations (Batchelor et al., 2009) are clearly constrained by distance. Of course, if pathogens establish in a new zone and the process is allowed to continue incrementally year after year, diseases can and have moved across countries in a decade without the aid of "modern transportation." However, at continental and intercontinental scales, movement of many diseases in a warming world is unlikely to have a linear relationship to distance because of the numerous means of long distance transport operating today.

\section{Biotic Assemblages and Host Range}

Because infectious diseases are components of species networks, simply arriving in a new location may be insufficient for establishment and creation of endemic lifecycles. A number of studies have shown that emerging and reemerging diseases, particularly those in the tropics, are predominantly zoonotic and/or vector-borne diseases (Daszak et al., 2000; Woolhouse and Gowtage-Sequeria, 2005; Wolfe et al., 2007). The principal ecological determinant for successful establishment for zoonotic and vector-borne disease success in a decadal time frame is probably a broad host range (Woolhouse and GowtageSequeria, 2005; Daszak et al., 2000). In recent years, a number of vector-borne viral diseases have migrated across or between continents through their ability to acquire new vectors (West Nile, Chikungunya) or utilize diverse and widely dispersed domestic (Rift Valley) or native (West Nile) animal hosts (Gould and Higgs, 2009). Importantly, the capacity to acquire new vector and host species often is facilitated by the capacity of the pathogen to evolve mutant strains that are efficiently acquired and transmitted by this new species.

Parasitic and infectious diseases with long, specialized, and/or especially complex life cycles involving multiple host species would logically be more challenged to establish themselves in new habitats by the need to find appropriate hosts and vectors. For example, the highly pathogenic 
Alveolar echinococcosis (fox tapeworm) has a northern distribution that is influenced by climate but constrained by landscape variables that determine host availability (Danson et al., 2003; Mas-Coma et al., 2008). Egg survival is dependent on ground moisture levels, but intermediate stages survive in rodents, and its definitive hosts are typically foxes, coyotes, and dogs. At large spatial scales across China and inner Mongolia, A. echinococcus distribution has become focal due to the interaction of the requirements for a physical environment that is moist and cool enough to allow for egg survival and for the grassland landscapes that support both high densities of small mammals and canine hosts (Giraudoux et al., 2006). High levels of forest cover or cleared agricultural landscapes reduce intermediate and/or definitive host densities.

It follows that for long-lived, host-specialized parasites, such as Echinococcus, it is likely that long time periods are required for the evolutionary changes required to enable dispersal to zones with insufficient host densities of its original species. However, some historical and paleontological studies of parasites suggest that host-switching behavior in parasites in response to ecological changes has been more common than generally thought and global climate changes are likely to produce broadening of parasite host ranges even for long-lived, nominally specialized parasites (Brooks and Hoberg, 2007).

By contrast, water-borne diarrheal diseases often are predicted to increase with climate change. Biogeographically restrictive interaction of diarrhea-causing pathogens with new hosts or other pathogens has received little attention to date in the context of climate change. An exception is a series of papers by Colwell and workers on associations of Vibrio cholera with copepods in zooplankton (Gil et al., 2004; Constantin de Magny et al., 2008).

For directly transmitted human diseases, the sorts of species network challenges may be even less of a constraint. Humans are most everywhere, highly mobile, and share most diseases readily. The principal biological barriers are host immune systems. Largely for these reasons we see rapid cross-national and continental movement and invasion by new viruses, such as seasonal influenza, SARS, and other coronaviruses. Although much of the climate change and disease discussion has focused on vector-borne diseases (Lafferty, 2009), the "biotic simplicity" of directly transmitted diseases, in concert with the climate sensitivity of viruses as discussed earlier, might argue that we should pay more attention to them in climate change discussions.

\section{Socioeconomic Conditions: Behavior, Public Health Infrastructure and Medical Interventions}

Although there has been little serious discussion that climate change will not impact infectious disease distributions, a view expounded by a number of authors (Reiter, 2008; Zell et al., 2008; Lafferty, 2009) discounts the relative role of climate change compared with other major influences on human disease. These factors include efficacy of control measures, such as vector control, sanitation, vaccination, and chemotherapy (Hay et al., 2002), as well as land use, urbanization, travel, wealth, and social behavior (Gubler et al., 2001; Sumilo et al., 2008).

Supporting this view, statistical mapping analyses (Rogers and Randolph, 2000; Hay et al., 2004) indicate that the spatial extent and number of countries reporting endemic malaria has shrunk toward the tropics from a much wider range during the twentieth century. The authors attribute this principally to better control of vectors and disease. Further support can be seen in the rapid reemergence of tick-borne encephalitis in central and eastern European states after the collapse of the Soviet Union (1970-2005) (Sumilo et al., 2008). Statistical comparisons of results of extensive socioeconomic surveys and public health data across five former Soviet states indicate that various socioeconomic, land use, and public health programs can explain most of the variation across countries in the spread of tick-borne encephalitis during this period. In this analysis, climate variables were not assessed, but significant unemployment, reversion of agricultural lands, reduced pesticide use, reduced chemotherapy, and individual exposure through increased field collection of wild foods appear to have contributed to rapid increases during the early 1990s.

The interaction of climate change, infectious diseases, socioeconomic conditions, and behavior is going to be increasingly important in the coming years and represents an exciting and complex area for research (Patz et al., 2005). For example, several authors have predicted mass migrations in response to climate change, particularly in response to worsening droughts in sub-Saharan Africa (Ramin and McMichael, 2009) (IPCC, 2007a). If borne out, it is likely that many diseases will travel with migrants, and in some cases will establish new infectious species or strains with significant effects on receiver populations (MacPherson et al., 2009). 
Similarly, availability of clean water and hygienic behavior are principal determinants of diarrheal disease outbreaks, and clean water will be increasingly in short supply in much of Africa and parts of Southeast Asia in the coming decades due to overexploitation and climate change (IPCC, 2007a). In an analysis of frequency all cause diarrhea in children younger than age 5 years in low- and middle-income countries, Lloyd et al. (2007) found that low mean monthly rainfall during the course of a year was significantly associated with disease. Surprisingly, neither temperature nor simple measures of socioeconomic development (GDP or GCP) were significant in this analysis of a disease type mostly managed by traditional public health measures, such as sanitation and education. Diarrheal diseases are produced by a diversity of bacterial, viral, and protozoan organisms. Strain diversity within a species is high locally (e.g., Jiang et al., 2000) around the world, and migration to new zones has significant implications for biologically naïve host populations.

Finally, given the importance and complexity of socioeconomic conditions on diseases, a variety of approaches and disciplines will be necessary to assess their effects on pathogen and parasite biogeography (Parkes et al., 2005). Macroeconomic and demographic modeling may offer underexploited utility in this regard. A recent paper by Tang et al. (2009) is instructive; they set out to disentangle the causality of a "climate-income trap model for human health" by examining national life expectancy statistics (45 African, 113 non-African countries) in a crosssectional analysis. Using a series of regression models and variation partitioning analyses to separate pure and combined effects of income and climate their findings support the hypotheses that: 1) income can moderate the adverse effect of climate on life expectancy (LE);2) as income grows climate will have less of an effect on LE; and 3) climate has a larger effect on LE in African countries than in non-African countries, and further that for African countries, climate has had a larger effect on LE than wealth.

\section{FinAL ThOUGHTS}

Debates over the impact of climate change on infectious disease emergence and migration are certain to continue in the years to come. Accumulation and validation of biological process models, and "ground truthing" these with statistical and mapping approaches help provide us greater clarity and ensure that we are asking the right questions.
Macroeconomic and demographic approaches may help us address some of the big questions related to the role of disease management capability. Critical to a greater understanding of these dynamics and more predictive power is greater availability of downscaled General Circulation Models to scales that are more relevant to community and landscape biology and public health.

I have not addressed time scales in any depth here, but they are extremely important aspects of biogeographic changes in relation to climate. Longitudinal studies on the multi-decadal time frames that climate change presents are a major challenge. But the time required for evolution of host range, for population dynamics of hosts and parasites to stabilize, and for medical and public health systems to adapt will all have major roles in determining biogeographic patterns of disease, and will all operate relatively independently. Creative approaches are needed to address this problem.

Debates about whether socioeconomic conditions or climate will be more important are probably more polarized than is productive. Both are clearly important. Both of these complex suites of variables are interacting with each other, and may do so in different ways for different diseases in different places. However, understanding these disease forcing factors and their interactions with each other are crucial to our ability to predict and prevent the most severe health outcomes.

The public health and medical community has made enormous strides in control of infectious diseases during the past half-century. Widespread availability of antimicrobial drugs, vector-control systems, diagnostics, vaccines, and increasingly sophisticated predictive models represent a powerful set of tools to protect public health from emerging diseases. However, it would be unwise to discount the potential importance of climate change, land use impacts, and other ecological determinants of future disease.

Historically, ecological factors, including climate, have been extremely important in determining both the range and severity of diseases. These factors are now aggravated by the near disappearance of antimicrobial drug development in the industrial pharmaceutical sector, dramatic reductions in training and support for vector control scientists and implementers, persistent scientific and financial challenges in developing new drugs and vaccines for even the most widespread diseases (e.g., HIV, malaria, TB), and medical workforce shortages in the poorest parts of the world. As our scientific capabilities to describe and model 
diseases and disease processes expands rapidly, it will be important to ensure that we understand the changing nature of our planet and continually adapt our systems and invest in them to meet the challenges.

\section{Open Access}

This article is distributed under the terms of the Creative Commons Attribution Noncommercial License which permits any noncommercial use, distribution, and reproduction in any medium, provided the original author(s) and source are credited.

\section{REFERENCES}

Aguirre-Macedo ML, Vidal-Martinez VM, Herrera-Silveira JA, Valdes-Lozano DS, Herrera-Rodriguez M, Olvera-Novoa MA (2008) Ballast water as a vector of coral pathogens in the Gulf of Mexico: the case of the Cayo Arcas coral reef. Marine Pollution Bulletin 56:1570-1577

Altizer S, Dobson A, Hosseini P, Hudson P, Pascual M, Rohani P (2006) Seasonality and the dynamics of infectious diseases. Ecology Letters 9:467-484

Arzt J, White WR, Thomsen BV, Brown CC (2010) Agricultural diseases on the move early in the third millennium. Veterinary Pathology 47:15-27

Batchelor NA, Atkinson PM, Gething PW, et al. (2009) Spatial predictions of Rhodesian Human African Trypanosomiasis (sleeping sickness) prevalence in Kaberamaido and Dokolo, two newly affected districts of Uganda. PLoS Neglected Tropical Diseases 3:e563

Beaumont LJ, Hughes L, Pitman AJ (2008) Why is the choice of future climate scenarios for species distribution modelling important? Ecology Letters 11:1135-1146

Brooks DR, Hoberg EP (2007) How will global climate change affect parasite-host assemblages? Trends in Parasitology 23:571-574

Constantin de Magny G, Murtugudde R, Sapiano MR, et al. (2008) Environmental signatures associated with cholera epidemics. Proceedings of the National Academy of Sciences USA 105:17676-17681

Danson FM, Graham AJ, Pleydell DR, Campos-Ponce M, Giraudoux P, Craig PS (2003) Multi-scale spatial analysis of human alveolar echinococcosis risk in China. Parasitology 127(Suppl):S133-S141

Daszak P, Cunningham AA, Hyatt AD (2000) Emerging infectious diseases of wildlife-threats to biodiversity and human health. Science 287:443-449

de la Rocque S (2008) Climate change: impact on the epidemiology and control of animal diseases. Introduction. Revue Science et Technique 27:303-308

Ebi KL, Woodruff R, von Hildebrand A, Corvalan C (2007) Climate change-related health impacts in the Hindu Kush-Himalayas. EcoHealth 4:264-270

Epstein PR, Diaz HF, Elias S, et al. (1998) Biological and physical signs of climate change: focus on mosquito-borne diseases. Bulletin of the American Meteorological Society 79:409-417
Fevre EM, Bronsvoort BM, Hamilton KA, Cleaveland S (2006) Animal movements and the spread of infectious diseases. Trends in Microbiology 14:125-131

Fowler HJ, Blenkinsop S, Tebaldi C (2007) Linking climate change modelling to impacts studies: recent advances in downscaling techniques for hydrological modelling. International Journal of Climatology 27:1547-1578

Gil AI, Louis VR, Rivera IN, et al. (2004) Occurrence and distribution of Vibrio cholerae in the coastal environment of Peru. Environmental Microbiology 6:699-706

Giraudoux P, Pleydell D, Raoul F, et al. (2006) Transmission ecology of Echinococcus multilocularis: what are the ranges of parasite stability among various host communities in China? Parasitology International 55(Suppl):S237-S246

Gould EA, Higgs S (2009) Impact of climate change and other factors on emerging arbovirus diseases. Transactions of Royal Society of Tropical Medicine and Hygiene 103:109-121

Gubler DJ, Reiter P, Ebi KL, Yap W, Nasci R, Patz JA (2001) Climate variability and change in the United States: potential impacts on vector- and rodent-borne diseases. Environmental Health Perspectives 109:223-233

Hawley WA, Reiter P, Copeland RS, Pumpuni CB, Craig GBJ (1987) Aedes albopictus in North America: probable introduction in used tires from northern Asia. Science 236:1114-1116

Hay SI, Guerra CA, Tatem AJ, Noor AM, Snow RW (2004) The global distribution and population at risk of malaria: past, present, and future. Lancet Infectious Diseases 4:327-336

Hay SI, Rogers DJ, Randolph SE, et al. (2002) Hot topic or hot air? Climate change and malaria resurgence in East African highlands Trends in Parasitology 18:530-534

IPCC (2007a) Climate Change 2007: Impacts, Adaptation and Vulnerability. In: Contribution of Working Group II to the Fourth Assessment Report of the Intergovernmental Panel on Climate Change, Parry ML, Canziani OF, Palutikof JP, van der Linden PJ, Hanson CE (editors), Cambridge, UK: Cambridge University Press, $976 \mathrm{pp}$.

IPCC (2007b) Climate Change 2007: The Physical Science Basis. In: Contribution of Working Group I to the Fourth Assessment Report of the Intergovernmental Panel on Climate Change, Solomon S, Qin D, Manning M, Chen Z, Marquis M, Averyt KB, Tignor M, Miller HL (editors), Cambridge, UK: Cambridge University Press.

Jiang SC, Matte M, Matte G, Huq A, Colwell RR (2000) Genetic diversity of clinical and environmental isolates of Vibrio cholerae determined by amplified fragment length polymorphism fingerprinting. Applied and Environmental Microbiology 66:148-153

Karesh WB, Cook RA, Bennett EL, Newcomb J (2005) Wildlife trade and global disease emergence. Emerging Infectious Diseases 11:1000-1002

Koelle K, Rodo X, Pascual M, Yunus M, Mostafa G (2005) Refractory periods and climate forcing in cholera dynamics. Nature 436:696-700

Kutz SJ, Hoberg EP, Polley L, Jenkins EJ (2005) Global warming is changing the dynamics of Arctic host-parasite systems. Proceedings of the Royal Society B: Biological Sciences 272:2571-2576

Lafferty KD (2009) The ecology of climate change and infectious diseases. Ecology 90:888-900

Lloyd SJ, Kovats RS, Armstrong BG (2007) Global diarrhoea morbidity, weather and climate. Climate Research 34:119-127

Mabaso ML, Vounatsou P, Midzi S, Da Silva J, Smith T (2006) Spatio-temporal analysis of the role of climate in inter-annual 
variation of malaria incidence in Zimbabwe. International Journal of Health Geography 5:20

MacArthur RH, Wilson EO (1967) The Theory of Island Biogeography, Princeton, NJ: Princeton University Press

MacPherson DW, Gushulak BD, Baine WB, et al. (2009) Population mobility, globalization, and antimicrobial drug resistance. Emerging Infectious Diseases 15:1727-1732

Martens P (1999) How will climate change affect human health? American Scientist 87:534-541

Mas-Coma S, Valero MA, Bargues MD (2008) Effects of climate change on animal and zoonotic helminthiases. Revue Science et Technique 27:443-457

Nakazawa Y, Williams R, Peterson AT, Mead P, Staples E, Gage KL (2007) Climate change effects on plague and tularemia in the United States. Vector Borne and Zoonotic Diseases 7:529-540

Ogden NH, Bigras-Poulin M, Hanincova K, Maarouf A, O'Callaghan CJ, Kurtenbach K (2008) Projected effects of climate change on tick phenology and fitness of pathogens transmitted by the North American tick Ixodes scapularis. Journal of Theoretical Biology 254:621-632

Paaijmans KP, Read AF, Thomas MB (2009) Understanding the link between malaria risk and climate. Proceedings of the $\mathrm{Na}$ tional Academy of Sciences USA 106:13844-13849

Parkes MW, Bienen L, Breilh J, et al. (2005) All hands on deck: transdisciplinary approaches to emerging infectious disease. EcoHealth 2:258-272

Pascual M, Ahumada JA, Chaves LF, Rodo X, Bouma M (2006) Malaria resurgence in the East African highlands: temperature trends revisited. Proceedings of the National Academy of Sciences USA 103:5829-5834

Pascual M, Chaves LF, Cash B, Rodo X, Yunus M (2008) Predicting endemic cholera: the role of climate variability and disease dynamics. Climate Research 36:131-140

Patz JA, Campbell-Lendrum D, Holloway T, Foley JA (2005) Impact of regional climate change on human health. Nature 438:310-317

Ramin BM, McMichael AJ (2009) Climate change and health in sub-Saharan Africa: a case-based perspective. EcoHealth 6:52-57

Reisen WK (2010) Landscape epidemiology of vector-borne diseases. Annual Review of Entomology 55:461-483
Reisen WK, Fang Y, Martinez VM (2006) Effects of temperature on the transmission of West Nile virus by Culex tarsalis (Diptera: Culicidae). Journal of Medical Entomology 43:309-317

Reiter P (2008) Global warming and malaria: knowing the horse before hitching the cart. Malaria Journal 7(Suppl 1):S3

Reperant LA (2009) Applying the theory of island biogeography to emerging pathogens: toward predicting the sources of future emerging zoonotic and vector-borne diseases. Vector Borne and Zoonotic Diseases 10:105-110

Rogers DJ, Randolph SE (2000) The global spread of malaria in a future, warmer world. Science 289:1763-1766

Shaman J, Kohn M (2009) Absolute humidity modulates influenza survival, transmission, and seasonality. Proceedings of the National Academy of Sciences USA 106:3243-3248

Shaman J, Pitzer VE, Viboud C, Grenfell BT, Lipsitch M (2010) Absolute humidity and the seasonal onset of influenza in the continental United States. PLoS Biology 8:e1000316

Sumilo D, Bormane A, Asokliene L, et al. (2008) Socio-economic factors in the differential upsurge of tick-borne encephalitis in Central and Eastern Europe. Reviews in Medical Virology 18:8195

Tang KK, Petrie D, Rao DS (2009) The income-climate trap of health development: a comparative analysis of African and NonAfrican countries. Social Science and Medicine 69:1099-1106

Wolfe ND, Dunavan CP, Diamond J (2007) Origins of major human infectious diseases. Nature 447:279-283

Woolhouse ME, Gowtage-Sequeria S (2005) Host range and emerging and reemerging pathogens. Emerging Infectious Diseases 11:1842-1847

Zell R, Krumbholz A, Wutzler P (2008) Impact of global warming on viral diseases: what is the evidence? Current Opinion in Biotechnology 19:652-660

Zhou XN, Yang GJ, Yang K, et al. (2008) Potential impact of climate change on schistosomiasis transmission in China. American Journal of Tropical Medicine and Hygiene 78:188-194

Zu Dohna H, Cecere MC, Gurtler RE, Kitron U, Cohen JE (2009) Spatial re-establishment dynamics of local populations of vectors of Chagas disease. PLoS Neglected Tropical Diseases 3:e490 